\title{
ECONOMIC EVALUATION OF AQUACULTURE INVESTMENTS UNDER CONDITIONS OF RISK AND UNCERTAINTY IN THE MEDITERRANEAN SEA
}

\author{
Filippo Sgroi, Salvatore Tudisca, \\ Anna Maria Di Trapani and Riccardo Testa \\ Department of Agricultural and Forestry Sciences, University of Palermo, Italy
}

Received 2014-05-15; Revised 2014-05-29; Accepted 2014-09-16

\begin{abstract}
This study aims to analyze, from a technical and economic point of view, the choice between alternative investments in aquaculture under conditions of risk and uncertainty. In particular, a comparative analysis has been conducted between an inshore and an offshore farm producing European sea bass in the Mediterranean Sea. The applied model refers to the theory of subjective probability, assigning a different probability to expected incomes during the investment period. Results show an economic convenience of inshore with respect to offshore farming.
\end{abstract}

Keywords: Competitiveness, Farms, European Sea Bass, Expected Incomes, Probability

\section{INTRODUCTION}

Capital investments, over the medium and long terms, that depend on entrepreneurial strategies, present a particularly unpredictable nature (Sgroi et al., 2014a; Volpato, 2000; Schotter, 1995). In the economic literature (Fontana and Caroli, 2006; Prestamburgo and Saccomandi, 1995), investment analyses are conducted on the presumption of certainty. However, the variables on which choices depend are actually random. Generally, the criteria used for the selection of mutually exclusive investments are represented by Net Present Value (NPV) and Internal Rate of Return (IRR) (Di Trapani et al., 2014a; Testa et al., 2014a; Tudisca et al., 2013a; 2011). NPV encounters known pitfalls concerning the interest rates to assign, since information on the profitability of invested capital is generally lacking. In the literature (Guerrieri et al., 1995; Nuti, 1987) some authors suggest adopting a rate oscillating between two levels, namely the rate of retrieval of necessary capital, at one extreme and the rate of return on equity invested in alternative uses, at the other (Pennisi and Scandizzo, 2003). When dealing with supposed interest rates, the typical and even marked flexibility responds to the need to take into account the highly subjective nature of entrepreneurial decisions. The latter are ultimately influenced by individual preferences and specific financial situations. Concern for the sheer speculation characterizing the selection of one rate over another may tend to tilt the balance in favor of the more invariant internal rate of return as the criterion of choice in investment analyses. However, with regard to future income, the degree of reliance on the conjectural, i.e., guesswork as to the likelihood of perfect knowledge, is one aspect having substantial weight for NPV and IRR alike. In sum, forecasts on income from medium-and long-term investments inevitably entail an inherent toll of risk and uncertainty. Given these premises, this study attempts an investment analysis of aquaculture-based sea bass production. The latter is quite important in Sicily, the largest island in the Mediterranean sea with a typical Mediterranean climate characterized by hot and dry summers and mild winters (Tudisca et al., 2014a; Grillone et al., 2014; 2012; 2009; Norman-López et al., 2013; Tudisca et al., 2013b; 2013c; Agnese et al., Corresponding Author: Filippo Sgroi, Department of Agricultural and Forestry Sciences, University of Palermo, Italy 
2008; D'Asaro et al., 2014; D'Asaro and Grillone, 2012; Di Trapani et al., 2014b), taking into account the above factors that characterize this type of endeavor. The paper aims to provide a contribution, in terms of knowledge, to the decision-making process of entrepreneurs so as to better orient their strategic business investments.

\section{MATERIALS AND METHODS}

In the economic literature pertaining to issues of business decisions, the conventional approach is to distinguish between situations of risk and those of uncertainty. In general, this distinction relies on whether or not the probability distribution of the event considered is known (Hall and Solomantine, 2008; Prestamburgo, 1969). The entrepreneur faced with mutually exclusive investments deals with risk whenever he or she is able to advance an opinion on single investments and then assess the probabilities of realizing the corresponding expected income, on the basis of relevant information. Conversely, uncertainty is characterized by a lack of such information, ruling out any valid estimate on the likelihood of achieving an expected income from either investment (Payzan-Lenestour and Bossaerts, 2011). Therefore, the entrepreneur incurs in risk whenever he or she decides to make a given investment, cognizant of a number of technical pieces of information (e.g., reports on farming conditions, fluctuations in prices, costs and inputs required and yields of goods intended for market) (Gu and Gudmestad, 2012). All these technical and economic factors that may impact on revenues and costs are accordingly factored into future expected incomes. In general, the entrepreneur's decision-making process is based on opinion formed through experience and that of others. Since prior experience enables one to assign a probability to each of the expected incomes for the duration of the economic life, entrepreneurs are said to perform under conditions of risk. When, however, the lack of information is such that no assessment (albeit subjective) about the probability of obtaining the expected results is feasible, in that case one operates under conditions of uncertainty (Raucher et al., 1999). Typical is the case of entrepreneurs who first attempt certain production activities in a new area, without being able to avail themselves of any inferences from the experience of others. So, in this case, the marketing strategy assumes a particular importance, not least for the profitability of the farm (Tudisca et al., 2014b). From the operational point of view, in business decisions the distinction between risk and uncertainty, based on the notion of subjective assessment of the probability of occurrence of an event, is not always possible. In particular, this happens for some investments in the medium and long term, characterized by fluctuations in the value of currencies or technical breakthroughs, that is phenomena that are difficult to prefigure. To remedy this situation, stochastic models can be applied to business decisions (Solari and Natiello, 2014). These models, by overcoming the determinism of conventional profitability indices, prove themselves better suited to grasp the essence of the entrepreneurial decisionmaking process, which is the result of rational choice in the light of appropriate information, while weighing economic and technical risk. It is precisely in this risk assessment that the usefulness of applying these methodologies is expressed. Arguably, the value of these models lies specifically in the interpretation and processing of information, albeit imperfectly by their very nature, nonetheless aiding to encompass all aspects of the economic reality in which the entrepreneur operates. In fact, they force the entrepreneur to think about the effects of a whole range of situations that might not even occur exactly as anticipated, but that constitute reference points that facilitate and render more rational those choices. However, at this point we wonder if the risk of investment in aquaculture can be assessed (Sgroi et al., 2014b; Santeramo et al., 2012; Seung, 2010). To answer this question we can say that whenever the probability distribution of the expected income can be estimated, the entrepreneur can measure the dispersion around its mean value and use this as a measure of risk (Liesch et al., 2011). However, the assessment of the probability of investments is very complex as it depends on many exogenous and endogenous variables that may affect the expected income. So, as mentioned above, when it is possible to estimate the probability distribution of an event, a risk measurement is likewise possible. In fact, considering the expected income in each period of the duration of the investment a random variable it is possible, for example by applying the internal rate of return, to obtain a probability distribution of possible levels of rates of yield corresponding to the different values that the random variable "expected income" can assume over the years of the investment (Hürlimann, 2013). If we plot the different levels of the internal rates of return on the $\mathrm{x}$ axis and the respective levels of probability on the $y$ axis, we obtain the graph of Fig. 1.

In this graph, $i_{o}$ is the internal rate of return with the highest probability, given a distribution over time of the random expected income from the investment under consideration. It should be noted that it is necessary to assume that the annual revenues from the investment be stochastically independent. 


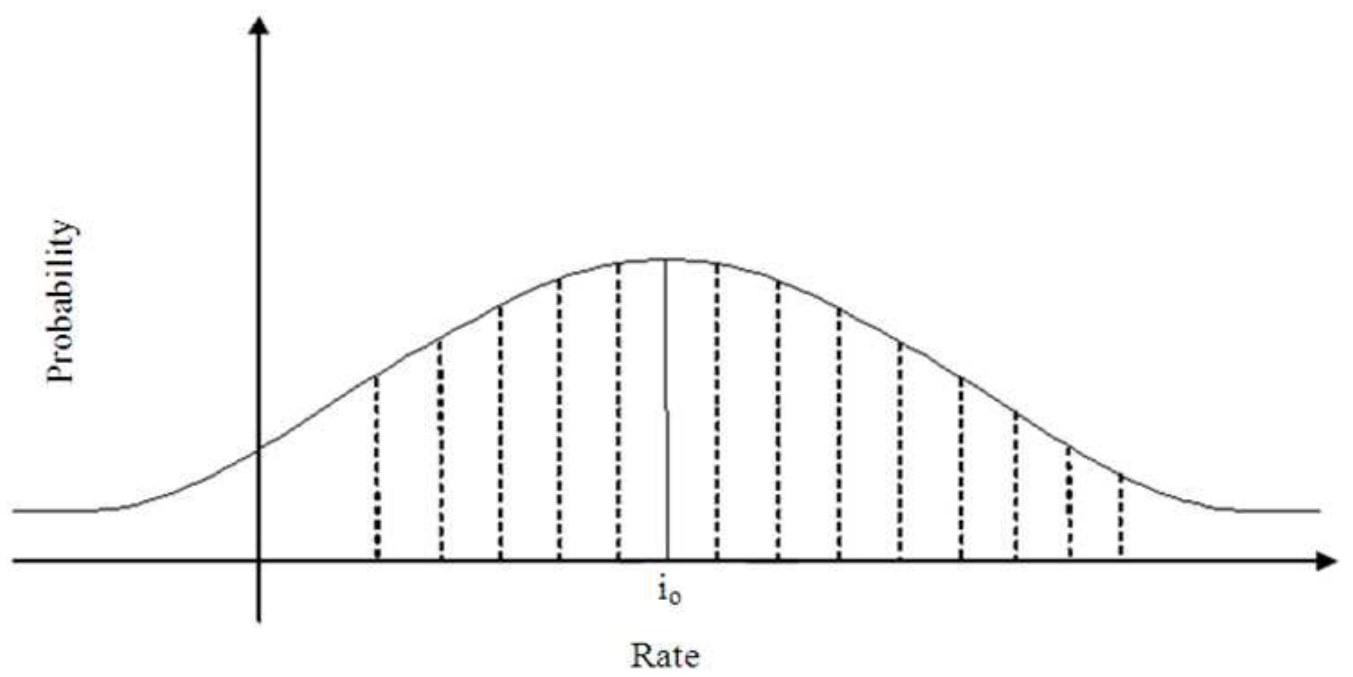

Fig. 1. Internal rate of return as function of probability of expected incomes

After making these theoretical premises, let us consider $\mathrm{K}$ aquaculture farms or installations, which can have productive cycles of different durations in terms of years, with Equation 1:

$$
n^{(1)} \neq n^{(2)} \neq n^{(3)}, \ldots \ldots ., \neq \mathrm{n}^{(\mathrm{K})}
$$

And hypothesize that the difference in each year of the cycle-with the exception of the set-up year-between revenues and costs attributable to each fish species farming facility is not set to any definite figure, but rather we consider it a discrete random variable to which we may assign some degree of probability. The costs of facility $x_{l}(\mathrm{j}=1,2, \ldots, \mathrm{k})$, as an element of certainty, is due to the fact that the employer, as a rule, knows with considerable certainty the cost of the fish farming facility under exam. Let us assume also that the annual revenues (arising from the difference between revenues and costs in the different years of the fish breeding cycle) are stochastically independent of each other and that from a certain year onwards the income is positive or at least not negative (i.e., that revenues are at least equal to if not greater than cost) (Yang and Jiang, 2014). Given these assumptions it is possible, by applying an appropriate methodology, to rank the investments considered according to preference. Let us assume that an entrepreneur decides to make an investment in aquaculture for the production of sea bass, after examining all the possible variations that can result in the productive combination of his or her company as a result of that choice, he or she is then faced with having to choose between an offshore or an inshore structure (Ferreira et al., 2014; Maricchiolo et al., 2011; Dempster et al., 2009; Whitmarsh et al., 2006).

Technical and economical data was provided directly by fish farmersby means of direct interviews (Testa et al., 2014b). The offshore installation comprises four cages enclosures of $7,000 \mathrm{~m}^{3}$ each for a total of $28,000 \mathrm{~m}^{3}$ of volume, located offshore; it usually produces $255 \mathrm{t}$ of $300 \mathrm{~g}$ sea bass annually, at the end of the 2-year fattening period. The inshore aquaculture fish farm, localized within the harbor facilities, is equipped with 40 cages enclosures of $700 \mathrm{~m}^{3}$ each for a total of $28,000 \mathrm{~m}^{3}$ of volume, that at full capacity yields $190 \mathrm{t}$ of $290 \mathrm{~g}$ sea bass annually, bred for 22 months. The source of data pertaining to the calculated selling price of $€ 6.10 / \mathrm{kg}$ was that of the sea bass fish farmers themselves. The latter data refer to two Sicilian aquaculture farms.

From peronal experience and from information obtained from other companies, the entrepreneur is able to estimate the economic life (which in this study was considered equal to 15 years according to information gathered from similar investments in the area of the study) and of the expected levels of production, prices and annual cost. In addition, in light of this information, the entrepreneur can attribute likelihoods of occurrence to the different levels of revenues and costs and therefore the difference in annual profits for each year of the economic life of the two fish-farming facilities examined.

By having a range of information, the allocation of a probability distribution, at different levels of profit for each year, becomes feasible. In addition, if our entrepreneur had sufficiently accurate information, both 
technical (production levels and the corresponding needs of production means), as well as economic (fluctuations in prices of goods and required means of production), the random variables would not be annual profit, but with increasing level of detail, could relate to the yield of the product and the requirements of means of production employed and their respective costs, thus simultaneously taking into account both technical and economic risks. Thus, a more analytical assessment of risk is allowed.

If the present value of the mean values and standard deviations of the annual incomes of the offshore facilities are respectively given by the following Equation 2 and 3:

$$
\begin{aligned}
& M(\text { Xoff })=\sum_{i=1}^{15} m_{i} \cdot v^{i} \\
& \sigma(\text { Xoff })=\left[\sum_{i=1}^{15} m \sigma_{i}^{2} v^{2 i}\right]^{1 / 2}
\end{aligned}
$$

where, $M$ and $\sigma$ represent, respectively, the mean values and standard deviations of the annual incomes; $v$ is the coefficient of anticipation $(1 / 1+i)$.

As regards inshore investment, instead, these values are respectively given by the following Equation 4 and 5:

$$
\begin{aligned}
& M(\text { Xin })=\sum_{i=1}^{15} m i \cdot v^{i} \\
& \sigma(\text { Xin })=\left[\sum_{i=1}^{15} m \sigma_{i}^{2} v^{2 i}\right]^{1 / 2}
\end{aligned}
$$

We have that if Equation 6:

$$
\frac{M(\text { Xoff })}{\sigma(\text { Xoff })}>\frac{M(\text { Xin })}{\sigma(\text { Xin })}
$$

The offshore investment is more profitable, whereas if Equation 7:

$$
\frac{M(\text { Xoff })}{\sigma(\text { Xoff })}<\frac{M(\text { Xin })}{\sigma(\text { Xin })}
$$

The inshore investment is more convenient.

Finally, in the case in which Equation 8:

$$
\frac{M(\text { Xoff })}{\sigma(\text { Xoff })}=\frac{M(\text { Xin })}{\sigma(\text { Xin })}
$$

No difference exists between the two investments.

To calculate profit, direct costs were subtracted from revenue. The costs include expenses related to the work required during the economic life, the cost of maintenance and repairs of investments, as well as for out-of-house materials and services (Sgroi et al., 2014c; 2014d; Tudisca et al., 2014c; 2014d).

\section{RESULTS AND DISCUSSION}

In the present study, we consider profit the discrete random variable, whose values are provided in Table 1 and 2.

As shown in the tables, the determinations of the considered discrete random variable "income" are three, namely a minimum level, below which the entrepreneur considers unlikely for it to drop, due to the difference between costs and revenues, a central level and a maximum level (Gandorfer et al., 2012).

Also included in the tables, next to each determination of the random variable, is the assigned likelihood of the corresponding value. Continuing in the discernment of the more preferable of the two potential investments, we proceed to determine the mean values and standard deviations of individual resultant incomes. The ratio of the mean value to the standard deviation can be equated to the index of prefer ability (Prestamburgo, 1970).

The preference for the latter, in the choice between the two alternative investments, derives from the fact that the probability that the internal rates of return, on the investments examined, exceed a specified interest rate, as the assumed term of comparison, is related to the mean value and the standard deviation of expected incomes.

A situation of indifference exists between the two investments, offshore and inshore respectively.

Table 3 shows the mean values and standard deviations for the investments examined by year of economic life. After choosing a discount rate of $6 \%$ (consistent with the present market), we calculated the present mean values and standard deviations of expected incomes for both offshore and inshore investments, respectively.

The values for the offshore installation were:

$$
\begin{aligned}
& \mathrm{M}(\text { Xoff })=€ 1,710.87 \\
& \sigma(\text { Xoff })=€ 89.02
\end{aligned}
$$

Thus, the present value of future expected incomes amounted to $€ 1,710.87$, while the present value of the standard deviations was equal to $€ 89.02$. 
Filippo Sgroi et al. / American Journal of Applied Sciences 11 (9): 1727-1734, 2014

Table 1. Expected incomes from offshore investment $€ / 1,000 \mathrm{~m}^{3}$

\begin{tabular}{lcccccc}
\hline Years & Min level $\mathrm{R}_{1}$ & $\mathrm{p}_{1}$ & Central level $\mathrm{R}_{2}$ & $\mathrm{p}_{2}$ & Max level $\mathrm{R}_{3}$ & $\mathrm{p}_{3}$ \\
\hline 1 & 0.00 & 0.00 & $-1,182.00$ & 1.00 & 0.00 & 0.00 \\
2 & 92.00 & 0.10 & 102.00 & 0.80 & 112.00 & 0.10 \\
3 & 368.00 & 0.10 & 378.00 & 0.80 & 398.00 & 0.10 \\
4 & 365.00 & 0.10 & 378.00 & 0.80 & 397.00 & 0.10 \\
5 & 357.00 & 0.10 & 367.00 & 0.80 & 395.00 & 0.10 \\
6 & 356.00 & 0.20 & 366.00 & 0.70 & 394.00 & 0.10 \\
7 & 349.00 & 0.20 & 368.00 & 0.70 & 388.00 & 0.10 \\
8 & 340.00 & 0.30 & 362.00 & 0.60 & 370.00 & 0.10 \\
9 & 330.00 & 0.30 & 340.00 & 0.60 & 370.00 & 0.10 \\
10 & 329.00 & 0.30 & 335.00 & 0.60 & 369.50 & 0.10 \\
11 & 320.00 & 0.40 & 330.00 & 0.50 & 365.00 & 0.10 \\
12 & 310.00 & 0.40 & 305.00 & 0.50 & 350.00 & 0.10 \\
13 & 299.00 & 0.40 & 304.50 & 0.50 & 349.00 & 0.10 \\
14 & 285.00 & 0.45 & 301.00 & 0.50 & 348.50 & 0.05 \\
15 & 280.00 & 0.45 & & 0.50 & 345.00 & 0.05 \\
\hline
\end{tabular}

Table 2. Expected incomes from inshore investment $€ / 1,000 \mathrm{~m}^{3}$

\begin{tabular}{|c|c|c|c|c|c|c|}
\hline Years & Min level $\mathrm{R}_{1}$ & $\mathrm{p}_{1}$ & Central level $\mathrm{R}_{2}$ & $\mathrm{p}_{2}$ & Max level $\mathrm{R}_{3}$ & $\mathrm{p}_{3}$ \\
\hline 1 & 0.00 & 0.00 & -994.00 & 1.00 & 0.00 & 0.00 \\
\hline 2 & 112.00 & 0.10 & 121.00 & 0.85 & 131.00 & 0.05 \\
\hline 3 & 310.50 & 0.10 & 321.00 & 0.85 & 335.00 & 0.05 \\
\hline 4 & 310.00 & 0.10 & 321.50 & 0.80 & 345.00 & 0.10 \\
\hline 5 & 298.00 & 0.10 & 320.00 & 0.80 & 335.00 & 0.10 \\
\hline 6 & 298.50 & 0.15 & 319.00 & 0.75 & 330.00 & 0.10 \\
\hline 7 & 220.00 & 0.20 & 239.00 & 0.70 & 249.00 & 0.10 \\
\hline 8 & 225.00 & 0.30 & 242.00 & 0.60 & 255.00 & 0.10 \\
\hline 9 & 227.00 & 0.30 & 244.00 & 0.60 & 258.00 & 0.10 \\
\hline 10 & 289.00 & 0.30 & 308.00 & 0.60 & 317.00 & 0.10 \\
\hline 11 & 290.00 & 0.40 & 306.00 & 0.50 & 320.00 & 0.10 \\
\hline 12 & 290.00 & 0.40 & 306.50 & 0.50 & 319.60 & 0.10 \\
\hline 13 & 289.00 & 0.40 & 306.50 & 0.50 & 319.50 & 1.00 \\
\hline 14 & 240.00 & 0.45 & 259.00 & 0.50 & 289.00 & 0.05 \\
\hline 15 & 239.00 & 0.45 & 258.00 & 0.50 & 288.00 & 0.05 \\
\hline
\end{tabular}

Table 3. Mean values and standard deviations of ex-pected incomes of investments $€ / 1,000 \mathrm{~m}^{3}$

\begin{tabular}{|c|c|c|c|c|}
\hline \multirow[b]{2}{*}{ Years } & \multicolumn{2}{|c|}{ Offshore } & \multicolumn{2}{|c|}{ Inshore } \\
\hline & Mean value & Standard deviation & Mean value & Standard deviation \\
\hline 1 & $-1,182.00$ & 0.00 & -994.00 & 0.00 \\
\hline 2 & 102.00 & 4.47 & 120.60 & 3.60 \\
\hline 3 & 379.00 & 7.00 & 320.65 & 4.55 \\
\hline 4 & 378.60 & 7.25 & 322.70 & 8.25 \\
\hline 5 & 368.80 & 9.23 & 319.30 & 8.39 \\
\hline 6 & 366.80 & 9.88 & 317.03 & 8.44 \\
\hline 7 & 366.20 & 10.44 & 236.20 & 8.62 \\
\hline 8 & 356.20 & 10.86 & 238.20 & 9.44 \\
\hline 9 & 340.00 & 10.95 & 240.30 & 9.62 \\
\hline 10 & 336.65 & 11.27 & 303.20 & 9.66 \\
\hline 11 & 329.50 & 12.75 & 301.00 & 9.84 \\
\hline 12 & 311.50 & 13.05 & 301.21 & 9.90 \\
\hline 13 & 307.00 & 14.28 & 588.35 & 10.40 \\
\hline 14 & 297.93 & 14.99 & 251.95 & 12.56 \\
\hline 15 & 293.75 & 15.58 & 250.95 & 12.70 \\
\hline
\end{tabular}


For the inshore farm the following values were obtained:

$$
\begin{aligned}
& \mathrm{M}(\text { Xin })=€ 1,574.84 \\
& \sigma(X i n)=€ 74.36
\end{aligned}
$$

Therefore, the present value of the average values of expected incomes amounted to $€ 1,574.84$ and the value of the standard deviations of annual revenues amounted to $€ 74.36$.

Thereby, given the distribution of expected incomes, the inshore facility is preferable to the offshore:

$$
\begin{gathered}
\frac{M(\text { Xoff })}{\sigma(\text { Xoff })}=\frac{1,710.87}{89.02}=19.21 \\
\frac{M(\text { Xin })}{\sigma(\text { Xin })}=\frac{1,574.84}{74.36}=21.18
\end{gathered}
$$

It is noteworthy that, had the comparison between the two investments been based solely on the, conveniently comparable, average returns, the offshore investment would have resulted the more profitable as well as in other studies (Kim and Lipton, 2011), despite the higher investment costs and production costs of offshore farm (Drach et al., 2013; Kaiser et al., 2010). In fact, the NPV of the offshore investment amounted to $€ 1,713.59$ against the $€ 1,464.75$ of the inshore investment. This situation is of particular relevance for investors whose preferences, all else being equal, favor investments with stable incomes rather than those subject to deviation (Elsner et al., 2012; Nietert, 2003).

\section{CONCLUSION}

In this study we have applied a stochastic criterion for choosing between mutually exclusive aquaculture investments. According to the illustrated application of this model we can affirm that, provided entrepreneurs have sufficient information about the investments under consideration, such as to enable them to form an opinion on the likelihood of the accuracy of their predictions, the model demonstrates considerable usefulness inasmuch as it tends to furnish entrepreneurs with a tool that is well suited to their actual operational scenarios. Accordingly, when information on the expected income from the investments considered are either lacking or unreliable, the model lacks applicable and the investment analysis cannot be conducted, if not on the premise of the presumption of certainty, which proves an often overly restrictive hypothetical grounds for the investment of capital in the medium and long term. It should be noted that the terms "information" and "opinions" are deliberately used so as to make clear that the theory underpinning the model is that of subjective probability, since it is not considered appropriate to apply objective or frequentist probability because very often the event considered is, for the most part, unique in character, both in time and space. The actual usefulness of this model should be sought in the fact that such instruments, although imperfect by their very nature, compel decisionmakers to grasp a range of situations that, even if not entirely accurate, nevertheless constitute reference points that render those choices more rational and more attuned to the endeavor of business.

\section{ACKNOWLEDGEMENT}

This study is a result of the full collaboration of all the authors. However, A.M. Di Trapani elaborated paragraph 5, F. Sgroi wrote paragraph 2, R. Testa wrote paragraph 3, while S. Tudisca elaborated paragraph 4.

\section{REFERENCES}

Agnese, C., F. D’Asaro, G. Grillone and A. Drago, 2008. Comparison of temperature data collected in urban and agricultural areas surrounding. Italian J. Agrometeorol., 13: 48-49.

D'Asaro, F., G. Grillone and R.H. Hawkins, 2014. Curve number: Empirical evaluation and comparison with curve number handbook tables in Sicily. J. Hydrol. Eng., DOI: 10.1061/(ASCE)HE.1943-5584.0000997

D’Asaro, F. and G. Grillone, 2012. Empirical investigation of curve number method parameters in the Medi-terranean area. J. Hydrol. Eng., 17: 1141-1152. DOI: 10.1061/(ASCE)HE.19435584.0000570

Dempster, T., Ø. Korsøen, O. Folkedal, J.E. Juell and F. Oppedal, 2009. Submergence of atlantic salmon (salmo salar L.) in commercial scale sea-cages: A potential short-term solution to poor surface conditions. Aquaculture, 288: 254-263. DOI: 10.1016/j.aquaculture.2008.12.003

Di Trapani, A.M., F. Sgroi, R. Testa and S. Tudisca, 2014a. Economic comparison between offshore and in-shore aquaculture production systems of European sea bass in Italy. Aquaculture. DOI: 10.1016/j.aquaculture.2014.09.001 
Di Trapani, A.M., R. Squatrito, M. Foderà, R. Testa and S. Tudisca et al., 2014b. Payment for environmental services for the sustainable development of the territory. Am. J. Environ. Sci.

Drach, A., I. Tsukrov, J. Decew, M.R. Swift and B. Celikkol et al., 2013. Design and modelling of submersible fish cages with copper netting for open ocean aquaculture marine. Proceedings of the 5th International Conference on Computational Methods in Marine Engineering, May 29-31, Hamburg, Germany, pp: 178-189.

Elsner, S., H.C. Krumholz and F. Richter, 2012. Residual income valuation and management remuneration under uncertainty: A note. Rev. Manag. Sci., 6: 333-359. DOI: 10.1007/s11846010-0058-X

Ferreira, J.G., C. Saurel, J.D. Lencart e Silva, J.P. Nunes and F. Vazquez, 2014. Modelling of interactions between inshore and offshore aquaculture. Aquaculture, 426-427: 154-164. DOI: $10.1016 /$ j.aquaculture.2014.01.030

Fontana, F. and M. Caroli, 2006. Economia e gestione delle imprese, McGraw-Hill, Milano.

Gandorfer, M., D. Pannell and A. Meyer-Aurich, 2012. Analyzing the effects of risk and uncertainty on optimal tillage and nitrogen fertilizer intensity for field crops in Germany. Agricult. Syst., 104: 615-622. DOI: 10.1016/j.agsy.2011.06.004

Grillone, G., G. Baiamonte and F. D'Asaro, 2014. Empirical determination of the average annual runoff coefficient in the Mediterranean area. Am. J. Applied Sci., 11: 89-95. DOI: 10.3844/ajassp.2014.89.95

Grillone, G., C. Agnese and F. D'Asaro, 2012. Estimation of daily solar radiation from measured air temperature extremes in the mid-mediterranean area. J. Irrigat. Drainage Eng., 138: 939-947. DOI: 10.1061/(ASCE)IR.1943-4774.0000480

Grillone, G., C. Agnese and F. D'Asaro, 2009. Estimation of solar radiation in Sicily by daily data maximum and minimum temperature. Italian J. Agrometeorol., 14: 84-85.

$\mathrm{Gu}, \mathrm{M}$. and O.T. Gudmestad, 2012. Treatment of uncertainties, risks and opportunities in cost and schedule estimates in the early phases of offshore projects. Proceedings of the 22nd International Conference Rhodes Offshore and Polar Engineering, Greece, Jun. 17-22, 641-649.
Guerrieri, G., F. Pennacchi and T. Sediari, 1995. Istitu-zioni di Economia e Politica Agraria, Edagricole, Bo-logna.

Hall, J. And D. Solomatine, 2008. A framework for uncertainty analysis in flood risk management decisions. Int. J. River Basin Manag., 6: 85-98. DOI: 10.1080/15715124.2008.9635339

Hürlimann, W., 2013. A Characterization of the Compound Multiparameter Hermite Gamma Distribution via Gauss's Principle. Sci. World J., PMID: 468418

Kaiser, M.J., Y. Yu and B. Snyder, 2010. Economic feasibility of using offshore oil and gas structures in the Gulf of Mexico for platform-based aquaculture. Marine Policy, 34: 699-707. DOI: 10.1016/j.marpol.2010.01.002

Kim, D. and D. Lipton, 2011. A comparison of the economic performance of offshore and inshore aquaculture production systems in Korea. Aquacult. Econ. Manag., 15: 103-117. DOI: 10.1080/13657305.2010.549165

Liesch, P.W., L.S. Welch and P.J. Buckley, 2011. Risk and uncertainty in internationalisation and international entrepreneurship studies: Review and conceptual development. Manag. Int. Rev., 51: 851873. DOI: $10.1007 / \mathrm{s} 11575-011-0107-\mathrm{y}$

Maricchiolo, G., S. Mirto, G. Caruso, T. Caruso and T. Bonaventura et al., 2011. Welfare status of cage farmed European sea bass (Dicentrarchus labrax): A comparison between submerged and surface cages. Aquaculture, 314: 173-181. DOI: 10.1016/j.aquaculture.2011.02.001

Nietert, B., 2003. Portfolio Insurance and model uncetainty. OR Spectrum, 25: 295-316.

Norman-López, A., E. Plagányi, T. Skewes, E. Poloczanska and D. Tennis et al., 2013. Linking physiological, population and socioeconomic assessments of climatechange impacts on fisheries. Fisheries Res., 148: 18-26. DOI: 10.1016/j.fishres.2012.02.026

Nuti, F., 1987. L'analisi costi benefici. Il Mulino. Bolo-gna.

Payzan-Lenestour, E. and P. Bossaerts, 2011. Risk, unexpected uncertainty and estimation uncertainty: Bayesian learning in unstable settings. PLoS Comput. Biol., 7: DOI: 10.1371/journal.pcbi.1001048

Pennisi, G. and P.L. Scandizzo, 2003. Valutare l'incertezza. L'analisi Costi Benefici Nel XXI Secolo. Giappichelli, ISBN-10: 8834833082, pp: 426.

Prestamburgo, M. and V. Saccomandi. 1995. Economia agraria. Etaslibri, Milano. 
Prestamburgo, M., 1970. Scelta tra investimenti alterna-tivi in agricoltura in situazioni di rischio e di incertezza. Rivista di Economia Agraria, 1: 89-108.

Prestamburgo, M., 1969. Il tasso di rendimento interno quale criterio di scelta tra investimenti alternativi in agricoltura. Rivista di Politica Agraria, 2: 45-63.

Raucher, R.S., M.M. Frey and P.L Cook, 1999. Benefit-cost analysis and decision-making under risk uncer-tainty: Issues and illustrations. IAHSAISH Publica-tion, 260: 141-149.

Santeramo, F.G., J. Di Pasquale, F. Contò, S. Tudisca and F. Sgroi, 2012. Analyzing risk management in mediterranean countries: The Syrian perspective. New Medit, 11: 35-40. PMID: 49851

Schotter, A., 1995. Microeconomia, G. Giappichelli Edi-tore. Torino.

Seung, C.K., 2010. Estimating economic information for fisheries using unequal probability sampling. Fisheries Res., 105: 134-140. DOI: 10.1016/j.fishres.2010.03.016

Sgroi, F., A.M. Di Trapani, R. Testa and S. Tudisca, 2014a. Strategy to increase the farm competitiveness. Am. J. Agric. Biol. Sci., 9: 394400. DOI: 10.3844/ajabssp.2014.394.400

Sgroi, F., S. Tudisca, A.M. Di Trapani, R. Testa and R. Squatrito, 2014b. Efficacy and efficiency of italian energy policy: The case of PV systems in greenhouse farms. Energies, 7: 3985-4001. DOI: 10.3390/en7063985

Sgroi, F., A.M. Di Trapani, R. Testa and S. Tudisca, 2014c. The rural tourism as development opportunity or farms. The case of direct sales in sicily. Am. J. Agric. Biol. Sci., 9: 407-419. DOI: 10.3844/ajabssp.2014.407.419

Sgroi, F., A.M. Di Trapani, R. Testa and S. Tudisca, 2014d. Economic sustainability of early potato production in the Mediterranean area. Am. J. Applied Sci., 11: 1598-1603. DOI: 10.3844/ajassp.2014.1598.1603

Solari, H.G. and M.A. Natiello, 2014. Linear processes in stochastic population dynamics: Theory and application to insect development. Sci. World J., DOI: 10.1155/2014/873624

Testa, R., A.M. Di Trapani, M. Foderà, F. Sgroi and S. Tudisca, 2014a. Economic evaluation of introduction of poplar as biomass crop in Italy. Renewable Sustainable Energy Rev., 38: 775-780. DOI: 10.1016/j.rser.2014.07.054
Testa, R., A.M. Di Trapani, F. Sgroi and S. Tudisca, 2014b. Economic analysis of process innovations in the management of olive farms. Am. J. Applied Sci., 11: 1486-1491. DOI:10.3844/ajassp.2014.1486.1491

Tudisca, S., A.M. Di Trapani, F. Sgroi, R. Testa and G. Giamporcaro, 2014a. Role of alternative food networks in Sicilian farms. Int. J. Entrepreneurship Small Bus., 22: 50-63. DOI: 10.1504/IJESB.2014.062130

Tudisca, S., A.M. Di Trapani, E. Donia, F. Sgroi and R. Testa, 2014b. Entrepreneurial strategies of Etna wine farms. Int. J. Entrepreneurship Small Bus., 21: 155-164. DOI: 10.1504/IJESB.2014.059470

Tudisca, S., A.M. Di Trapani, F. Sgroi and R. Testa, 2014c. Organic farming and economic sustainability: The case of Sicilian durum wheat. Quality-Access Success, 15: 93-96.

Tudisca, S., A.M. Di Trapani, F. Sgroi and R. Testa, 2014d. Economic evaluation of PDO introduction in Sicilian orange farms. Quality-Access Succ. 14 139: 99-103.

Tudisca, S., A.M. Di Trapani, F. Sgroi, R. Testa and R. Squatrito, 2013a. Economic analysis of PV systems on buildings in Sicilian farms. Renewable Sustainable Energy Rev., 28: 691-701. DOI: 10.1016/j.rser.2013.08.035

Tudisca, S., A.M. Di Trapani, F. Sgroi and R. Testa, 2013b. Marketing strategies for Mediterranean winer-ies competitiveness: The case of Pantelleria. Q. Access Success, 14: 101-106.

Tudisca, S., A.M. Di Trapani, F. Sgroi and R. Testa, 2013c. The cost advantage of Sicilian wine farms. Am. J. Applied Sci., 10: 1529-1536. DOI: 10.3844/ajassp.2013.1529.1536

Tudisca, S., F. Sgroi and R. Testa, 2011. Competitiveness and sustainability of extreme viticulture in pantelleria island. New Medit, 10: 57-64.

Volpato, G., 2000. La gestione dell'impresa. Cedam, Padova.

Whitmarsh, D.J., E.J. Cook and K.D. Blac, 2006. Searching for sustainability in aquaculture: An investigation into the economic prospects for an integrated salmonmussel production system. Marine Policy, 30: 293-298. DOI: 10.1016/j.marpol.2005.01.004

Yang, H. and F. Jiang, 2014. Stochastic methods for a class of jump-diffusion stochastic pantograph equations with random magnitude. Scientific World J., PMID: 589167. 